\title{
'Marginalizing' health: employing an equity and intersectionality frame
}

\author{
'Marginalizando' a saúde: empregando uma abordagem de equidade e \\ interseccionalidade
}

Deepa Venkatachalam', Gargi Mishra', Adsa Fatima', Sarojini Nadimpally'

DOI: 10.1590/0103-11042020S109

\begin{abstract}
The understanding that the drivers of inequities are multiple and intersecting is critical for health policy formulation and implementation. An intersectionality analysis reveals these relationships and allows a nuanced grasp of how health inequities are framed and understood. Using global statistics and other examples, the paper argues the significance of an intersectionality analysis in unravelling the disproportionate impact of inequity and the implications for the health and lives of persons experiencing these multiple discriminations. Attention to this, challenges the assumption of homogeneity and helps to visibilize lived realities. A few examples of acts of resistance are cited by the authors that have attempted to amplify the voices and knowledge of those whose realities are otherwise invisibilized by prevailing inequities, policies and discourses. 'Marginalizing' health thus implies an intersectional understanding of inequity as well as challenging and changing prevailing socio-political structures.
\end{abstract}

KEYWORDS Health. Intersectionality. Equity. Social discrimination.

RESUMO O entendimento de que os fatores motivadores das desigualdades são múltiplos e se cruzam é fundamental para a formulação e para a implementação de políticas de saúde. Uma análise de interseccionalidade revela essas relações e permite uma compreensão diferenciada de como as iniquidades em saúde são estruturadas e compreendidas. Usando estatísticas globais e outros exemplos, o artigo argumenta a importância de uma análise de interseccionalidade para desvendar o impacto desproporcional da desigualdade e as implicações para a saúde e a vida das pessoas que sofrem essas múltiplas discriminações. Essa abordagem desafia o pressuposto de homogeneidade e ajuda a visibilizar as realidades vividas. Alguns exemplos de atos de resistência são citados pelos autores que tentaram ampliar as vozes e o conhecimento daqueles cujas realidades são, de outro modo, invisibilizadas pelas iniquidades, políticas e discursos predominantes. A 'marginalização' da saúde implica, portanto, um entendimento interseccional da desigualdade, assim como em enfrentar e mudar as estruturas sociopolíticas predominantes.

PALAVRAS-CHAVE Saúde. Interseccionalidade. Equidade. Discriminação social.

1 Sama Resource Group for Women and HealthMalviya Nagar, India. sama.womenshealth@gmail. com 


\section{Introduction}

Between May and June 2019, over 150 children died in the Muzaffarpur district of Bihar, a state in eastern India, due to an outbreak of Acute Encephalitis Syndrome (AES), which has been a recurring annual phenomenon during these months for several years now. The AES deaths were attributed to a combination of factors such as chronic malnutrition, consumption of unripe litchis (a fruit grown locally), heat wave, and a poorly functioning health care system.

In India, the Community Health Centres (CHCs) are the third tier of the network of rural health care facilities of the public health system and is a referral centre for the Primary Health Centres (PHCs). The CHCs in Bihar experience an overall shortfall of 86 percent in specialist doctors. Merely one-third of the CHCs have newborn care units - compared to the national average of 84 per cent - and only 42 percent of the PHCs are open 24 hours per day every day of the week. This clearly reflects the abysmal situation of healthcare in the state,and more so in Muzaffarpur, the district where the deaths took place.

A majority of the children who died were from two administrative blocks within the district. They were mostly from dalit/Scheduled Caste (SC) families, while a few were from extremely poor families of Other Backward Classes (OBC). Scheduled Castes (SCs) also known as 'dalit' and Scheduled Tribes (STs) also known as 'adivasi' are among the most disadvantaged socio-economic groups in India based on caste and ethnicity identity respectively. The families of the deceased children were dependent on small and marginal farming, daily wage labour and seasonal migration. Malnutrition was common amongst the children in these families. Moreover, almost 64 per cent of the children who died due to AES were girls.

The deaths clearly point to inequitable access to the social determinants of health ${ }^{\mathbf{1}}$, and it is the complex intersection of these determinants that ultimately caused the deaths. An analysis of the multiple and intersecting social locations (caste, gender, class, geography) and social determinants (nutrition, poor sanitation,migration, poor health care, lack of awareness) provides insights into the possible differences in health outcomes. In this context, it exemplifies the reasons for the higher rates of deaths amongst girls from certain caste groups and provides evidence for policy measures to be undertaken at multiple levels to ensure that such deaths are prevented.

Such an intersectional analytical framework is helpful in understanding the interaction of people's diverse social locations and their relationship with structures and systems of power - social, political and economic institutions, including governments, educational institutions, religious institutions, laws and policies (domestic and international), media, etc. These multiple, complex, and dynamic intersections generate and maintain privilege and oppression.

The recognition of the drivers of inequities as being multiple and intersecting is significant for health policy formulation and implementation. It is an important tool for

multi-level analysis of intersecting factors, processes and structures impacting health experiences, and its principles lead to questions regarding how, and whose health issues are framed and understood $2(\mathbf{( 1 8 )}$.

\section{Origins of intersectionality}

The term 'intersectionality' was first coined in 1989 by Kimberle Crenshaw, an American legal academic and civil rights activist in her paper Demarginalizing the Intersection of Race and $\mathrm{Sex}^{3}$ to analyze the racial and gender discrimination in the legal system of the United States of America. However, as Crenshaw has also acknowledged, the understanding of intersectionality can be traced much earlier, to nineteenth-century black feminist activism 
and writings of activists as well as to indigenous women's activism ${ }^{4}$. A black lesbian collective, for instance, argued in 1977 that women like themselves needed an identity politics precisely because they were getting lost within the simultaneous workings of race, patriarchy and heterosexuality within systems of imperialism and capitalism ${ }^{5}$. Although the term intersectionality features more recently in Indian academic discourse, insights into diverse social identities and marginalization have existed much longer; for example, the anti-Brahmin struggles of Tamil Nadustate or the Dalit literary campaigns in Maharashtra state in the 1960s. However, the intersectionality discourse, several scholars opine, has remained largely US and Euro centric ${ }^{6}$.

\section{Intersectionality and political economy}

Equity is a central tenet in an intersectionality analysis as also in a political economy analysis. Some scholars suggest that the intersectionality and feminist political economy frameworks are similar; they are likely to inform and expand each other's frameworks and analyses ${ }^{7}$. Both frameworks hold health equity and gender, race, ethnicity as central to their analysis. While political economy analysis has largely focused on social class, feminist political economists have for long emphasized that

class has to be re-conceptualized through race and gender within regional, national, and international contexts. [...] Gender, race/ ethnicity and regionality/nationality interact with class in various ways with one being more salient than another at different points in time ${ }^{\mathbf{7 ( 6 2 )} \text {. }}$

Both intersectionality and feminist political economy provide important frameworks for analysis of health equity including access to health care.

\section{Achieving health equity: the role of intersectionality}

Achieving health equity is one of the foremost objectives of public health.

Health equity implies that everyone should have a fair opportunity to attain their full health potential and that no one should be disadvantaged from achieving this potential8.

Therefore, any analysis of health must employ a health equity lens that seeks to identify the differences in health status, reasons for the differences, who experiences them and how,and when they are experienced. Essentially, achieving health equity is premised on interrogating the relationships of social, economic and political power.

The Declaration of Alma-Ata in 1978 was a milestone in this regard, which proclaimed 'Health for All' and emphasized the unacceptability of health inequities between and within nations ${ }^{9}$. According to the Declaration,

Economic and social development, based on a New International Economic Order, is of basic importance to the fullest attainment of Health for All and to the reduction of the gap between the health status of the developing and developed countries. The promotion and protection of the health of the people is essential to sustained economic and social development and contributes to a better quality of life and to world peace ${ }^{\mathbf{9 ( 1 )}}$.

In the pursuit of addressing the root causes of ill-health, the Declaration's iteration for the need to restructure the global economic order and its emphasis on enabling of resources for quality health care are more relevant now than ever before.

Today, evidence of the growing inequalities globally is stark ${ }^{\mathbf{1 0}}$ :

- The richest one percent of the people has owned more wealth than the rest of the planet since 2015 . 
- Eight men now own the same amount of wealth as the poorest half of the world.

- The incomes of the poorest 10 percent of people increased by less than USD 3 a year between 1988 and 2011, while the incomes of the richest one per cent increased 182 times as much.

- In the US over the last 30 years, the growth in the incomes of the bottom 50 percent has been zero, whereas incomes of the top one percent have grown 300 per cent.

- In Vietnam, the country's richest man earns more in a day than the poorest person earns in 10 years.

These statistics are unambiguous indicators of a very unequal world. Forty years after Alma-Ata, the gaps in inequities in health across and within countries have only widened. Currently, the global discourse on health is focused mainly on how to operationally bring health within the reach of all, without really addressing the inequities in the structural determinants of health. The statistics also conceal who are disproportionately impacted by these inequities by the interconnected structural determinants of gender, race, caste, ethnicity, sexuality, disability, geography and what are the implications for the health and lives of persons experiencing these multiple discriminations.

In Health for All, the 'for all' implies that everyone must have equal access to the determinants of health including health care, and the measures for this access, which entails transformation in social, economic and political contexts, must be enabled.

However, analysis of even the Alma-Ata documents suggests the need for strengthened interrogation of patriarchy and other intersecting factors of marginalization including race, ethnicity, sexuality, religion, caste, ability, etc."1, in their reference to women's unpaid work as also with regard to the involvement of the community in all stages of health planning. It is necessary that simplified and homogenized notions of communities and identities as well as the hegemony of knowledge and health systems are challenged"1.

Women, for example, are amongst the poorest in the world. Women from marginalized communities are engaged in the least secure, poorest paid and amongst the most stigmatized, and harmful work. However, women's domestic and other care work is essentialized and unpaid. It is neither recognized adequately as work, nor is its ample contribution to the economy acknowledged. Further, in today's context of increasing privatization and contractual forms of labour directed by structures of neoliberal globalization, this work is invariably located at the intersections of class and gender, race, caste, ethnicity, with varied and serious consequences for the health and living conditions of the women involved. In India, for example, over 800,000 community health care workers, and over a million workers of the Integrated Child Development Services (ICDS) scheme,all of whom are women and engaged in India's public health and child development programme, are employed on a contractual basis with poor irregular remuneration and security ${ }^{\mathbf{2}}$.

Moreover, the very understanding of 'health' founded on 'what systems of knowledge about health prevail', 'whose knowledge is privileged and included', "who are excluded in the process of construction of this knowledge"2(10) is critical to challenge the dominant discourses on the political economy of health. Responses to these questions reflect the relationships of power and intersecting discriminating factors that privilege some knowledge while marginalizing others. For example, the allopathic and biomedical systems of health which dominate globally, invariably reflect and reinforce patriarchy, hetero-normativity, class and caste biases that are deeply rooted in colonialism, capitalism, neoliberal globalization and privatization, and which serve to create, maintain and replicate systems of power"1. Globally this knowledge and 
the health system based on it, largely exclude other knowledge systems of health or permit them in ways that are limiting and not transformative. These marginalized systems do not often pursue bio-medical models of medicine and understanding of health, but they are equally responsible for reinforcing patriarchy, ethnicity and caste, and excluding the knowledge of dalit, indigenous and other marginalized communities, especially women from such communities ${ }^{11}$.

In India and in many other parts of the world, the extensive knowledge around birthing and healing has been assimilated and practiced by non-literate women from marginalized communities for many generations. However, this knowledge has been marginalized through processes of colonization and allopathy as well as by motivations of gender and caste hierarchies. Increasingly, the intersecting of political economy and the "politics of knowledge"11(1-8) has alienated indigenous communities from their ecological resources - access to forests, water, land, etc., and thereby their knowledge - through forced evictions, displacements due to conflicts and other economic or social motivations, with the resources pro-actively being handed over to private for-profit corporations.

The pluralism of health and medicine, evident in the everyday lives of tribal communities, need to be critically understood and built upon, while discouraging patent regimes that seek to appropriate their traditional knowledge ${ }^{13(23)}$.

Ultimately,the evidence points to profit rather than health and social justice - as the driver of health research and development ${ }^{\mathbf{1 4}}$, and the promulgation of hegemonic health knowledge.

\section{In a UHC world}

The current catch phrase of the global health discourse is Universal Health Coverage (UHC). Not only is it in sharp contrast with the vision of Primary Health Care (PHC) envisaged in the AlmaAta declaration of 1978 - which called for the building of health systems that would provide comprehensive care, that would be integrated and organized to promote equity, and driven by community needs its limited vision of 'coverage' is merely one aspect of universal health 'care'15(81).

With regard to health status and access to health services, a study found that at least 400 million people lacked access to at least one of the seven essential services relating to health care, such as family planning, antenatal care, skilled birth attendance, child immunization, antiretroviral therapy, tuberculosis treatment, as well as access to clean water and sanitation $^{16}$. The report indicated that merely 37 per cent of people living with HIV received antiretroviral treatment, with only just over a half, i.e. 55 per cent of new tuberculosis cases reported received diagnosis and treatment. While this reflects the overall poor access to health care, the following statistics indicate the inequities globally by class, race, gender and other determining factors:

- Developing countries, for instance, account for 99 per cent of maternal deaths in the world;

- 95 percent of deaths due to tuberculosis are in developing countries;

- Children from the poorest 20 percent of households are nearly twice as likely to die before their fifth birthday as compared with children in the richest 20 per cent;

- In the USA, African-Americans represent 13 percent of the population but experience almost half of all new HIV infections ${ }^{\mathbf{1 6}}$;

- In India, of the 2.1 million people are living with HIV ${ }^{17}$, out of which 40 percent new cases annually are women ${ }^{18}$. 
Worsening inequities impacting health within countries are also evident - India's global gender gap ranking, for example, was 108 out of 149 countries in 2018 . The gendered status of health and health care, which is apparent from the 'health and survival' score, has fallen from a lowly 103 (2006) to an unacceptable 141. Further, the worsening gender gap on other indicators that also determine health and healthcare is evident - in the area of 'economic participation and opportunity' India's rank has fallen from 110 to 139; with regard to 'educational attainment' the current rank is 112 from an erstwhile 102, while it has reduced from 20 to 15 in 'political empowerment'19.

While gender disparities are evident in the health status and access to healthcare, its intersections with race, caste, ethnicity, sexual identity, ability, age, etc., shape the extent and experience of health care. Attention to these factors challenges the assumption of homogeneity and helps to visibilize the lived realities.

Another disconcerting trend is the push towards anti-immigration and the extremely excluding stance by States against people seeking refugee status, shelter and safety from contexts of economic, social and political upheaval. This is not only true for the global North, but for the global South too. While goods and capital flows are becoming more seamless with neoliberal globalization, movement of people and their labour is increasingly facing multiple hurdles and closed borders, that have serious consequences on their health and lives.

On the one hand it is now easy to become 'friends' on Facebook, connect with virtual strangers, but on the other, xenophobia, homophobia, transphobia, Islamophobia and the likes that are rooted deeply in colonialism, racism, casteism, patriarchy, etc. are deepening20(1).

The UHC era is simultaneously marked by States withdrawing from their obligation to provide health care, the impact of which is borne disproportionally by the marginalized.
Privatization of health care and an emerging unregulated private sector in many countries have given a boost to burgeoning pharmaceutical industries whose research and development priorities are dominated by anticipated profit rather than need, while the ever-increasing costs of health care leave an unacceptably large number of people out of the ambit of timely and quality health care. The State as a political entity is also gendered, caste-ist, and disability - blind. Health service provisioning continues to focus on maternity and fertility control rather than on the varied health needs of a diverse range of women and marginalized persons across geography and culture, including their mental and occupational health. States 'adherence to and consolidation of patriarchal, caste and sexuality norms violate hard earned rights through discriminatory policies such as coercive population policies, non-availability of access to abortion services, as well as privatization, levying of user fees, etc.

The current UHC discourse proposes a shift towards ensuring wider 'coverage' and reducing financial costs for health care. While this is important, the approach does not address deep-seated structural inequalities that have remained critical barriers to receiving comprehensive quality health care. With countries increasingly playing a restricted role of health care financing and purchasing (from private sector) while withdrawing from provisioning, it is likely to worsen access to health care, particularly for the most marginalized.

This extremely precarious context necessitates renewed positioning of 'health as a human right' towards Health for All and attention to the growing inequities in access to the social, economic and political determinants of health and health care. The struggle for health is a struggle for a more just and equal world and must act upon how existing public health systems can be universal and equitable,which is tragically but inevitably outside the ambit of the current UHC discourse. In such a context, there is need currently and in the 
longer term for solidarities between diverse movements and alliances that are able to gainfully and collectively inform the UHC discourse to enable transformative change in Health for All people. For instance,the Alliance for Gender Equality and UHC and the People's Health Movement (PHM)have been informing the UHC process from the different frameworks of gender equality and political economy respectively. There is need for greater intersections between alliances, social movements and discourses on gender, caste, race, sexuality, disability with health.

\section{Resist! Act! Health for All now!}

Situations of oppression and deprivation have time and again motivated marginalized communities to resist dominant systems of knowledge, health and power. The following are some examples of such acts of resistance, which have attempted to amplify the voices and knowledge of those whose realities are invisibilized by prevailing inequities, policies and discourses ${ }^{2}$.

\section{From India: struggle by Baiga (tribal)women in Chhattisgarh to access sterilization}

Women from the Baiga community - an ethnic group categorized as a Particularly Vulnerable Tribal Group (PVTG) in the state of Chhattisgarh in central India, filed a Public Interest Litigation in the High Court to demand their access to sterilization (permanent long-term contraception) services provided through government programs.

The Baigas are a forest community who practice shifting cultivation. Since the 1960 s, the Baigas have been subject to forced evictions by the government in the name of conservation, that have destroyed their way of life and resulted in an unprecedented decline in their numbers. In 1979, a State Government order restricted sterilization services for women from tribal communities that were earlier referred to as 'Primitive' Tribal Groups (PTGs) and currently as Particularly Vulnerable Tribal Groups (PVTGs). This order was challenged by the Baiga women, their families along with the health activists and human rights activists engaging on this issue in the High Court, following which it was revoked in 2018.

This order, however, is situated in the same context of otherwise poor access to the social determinants of health and health care, coercive population control policies and targets, aggressive push for permanent methods of contraception, primarily sterilization,for women from other tribal and marginalized communities. Nevertheless, the selective pro-natalist stance of the State violated the rights of the women Baiga communities in Chhattisgarh to bodily autonomy and agency, and to decide about their reproductive lives.

The resistance by the Baiga women was against the dominant perspective of the patriarchal, paternalistic State that invisibilized their lived realities, which were otherwise subsumed under the larger category of tribal women, many of whom had been part of struggles against forced sterilizations, poor quality of care and complications/ deaths resulting from poor and negligent government services.

Analysis of the struggle is to understand the experiences of the Baiga women as outcomes of their relationship with patriarchy, colonialism and ethnicity/caste bias in a larger context that is constructed by a State that has been violating the reproductive rights of women, especially women from marginalized caste, indigenous, religious communities through its coercive population and fertility control agenda and programs. 


\section{From Bolivia: reframing health - The concept of living well}

'Living well' or buen vivir constitutes the fundamental theoretical foundation of the new state in Bolivia, oriented to building development alternatives based on recovering national cultural identity and state sovereignty, building a participatory democracy, and restoring natural resources. It draws on the Andean and Amazonian people's world view. During the 300 years of Spanish colonialism and 200 years of Creole colonialism - when the native indigenous peoples of Bolivia were reduced to slavery and feudal serfdom, and faced ruthless discrimination and exploitation indigenous rebellions and uprisings were hoisting the banner of 'living well' as a development alternative. Indigenous people are leading the social transformation of Bolivia along with the peoples' movement and that of wage earners and the self-employed. Together they launched the struggle against colonialism, the oligarchy and neoliberal capitalism, setting the course for political change and mapping out plans for development of the new plurinational state. They proclaimed the emancipation of native peoples, communitarianism and equal rights and opportunities for all cultural, ethnic and language groups, and called for reclaiming a society free of capitalist exploitation. Bolivia today is undergoing a complex process of transition that has been described as post-capitalist, which involves searching for types of development that are alternatives to capitalism.'Living well' is contributing, at a structural level, to the dismantling of colonialism and neoliberalism by promoting communitarianism and inter-culturalism, towards restoring social solidarity, reciprocity, complementarity and equity as the guiding principles for action in the health sector ${ }^{21}$.

\section{From India: queering the health discourse}

Until recently, same sex relationships between consenting adults was criminalized in India by the colonial-era Section 377 of the India Penal Code, which penalized 'carnal intercourse against the order of nature'. A long drawn battle with many twists and turns, advances and losses, finally culminated in the 2018 judgment of the Supreme Court, which decriminalized homosexual, consensual sex between adults ${ }^{22}$. The campaign against Section 377 witnessed intersections of various organizations and movements working on diverse issues ranging from women's rights to disability, land, food, health rights and others.

In 2014, the Supreme Court had accorded recognition to transgender and intersex people as the 'other' gender thereby paving the way for them to claim their fundamental rights guaranteed under the constitution as equal citizens in the National Legal Services Authority (Nalsa) versus Union of India ${ }^{23}$. While these are critical outcomes of years of collective resistance, they need to be sustained to challenge more recent laws that are not in conformity with the above; these positive legal shifts also do not automatically imply guarantees for access to a range of information and services, including health care in ways that are transformative and challenge dominant normative structures. The struggle continues.

\section{From Greece: the solidarity pharmacies}

We fight all together against the abolition of social rights, against individualism and against fear. We fight for the consolidation of the principles of solidarity, justice and human dignity [The Pharmacy of Solidarity at Patisia] ${ }^{24}$. 
The 'Pharmacy of Solidarity', was a community clinic for children's health in the Patisia, a suburb of Athens. It was supported by the city council and run by a school doctor. Subsequently, it was closed due to austerity measures. It now brings together parents, teachers, activists and volunteers who raise resources through donations and continue to run the clinic with the same objectives. The Pharmacy provides free services for people without social insurance, including immigrants and the homeless. It also works closely with a network of doctors from the Solidarity Clinics facilitating referrals for access to health care for the most vulnerable people in the area. The Solidarity Pharmacy and Clinic provided services for the large number of refugees who arrived in 2015 in the city by working shifts. This initiative has also led to others - for example, providing free food and teaching for children from poor and vulnerable communities.

The above-mentioned examples are only a few of the many resistances and struggles that are taking place in all global regions. They also reiterate the significance of social justice and equity to achieve health and also the various contexts that create and reinforce marginalization. The understanding of the intersections of these contexts and marginalization is critical to forge alliances and solidarity to achieve the goal of Health for All.

\section{The way ahead}

Any tool of analysis of health must be premised on principles of social justice, which necessitates deeper analysis of prevailing inequities and the diverse factors that determine them. Intersectionality offers the possibility of an analytical tool that may be able to surpass this, delve deeper and nuance the understanding of inequities. It allows the centering of the perspectives of groups facing multiple oppressions and invisibilization, and for health to be viewed in the context of communities and societies, and not merely as diseases and deficiencies in an individual's body. It thus calls attention to the broader social, political, economic and cultural processes and structures that produce and sustain health disparities. Changing health outcomes then demands a restructuring and changing of other socio-political structures. In the context of the deaths of children due to AES in Bihar, an intersectional approach calls attention to the historical caste discrimination in the areas, their disenfranchisement and inability to own land, access the public distribution system and gain stable and well-paying work, and their reliance on seasonal litchi harvests for earning wages. Addressing AES deaths is therefore not a question of merely medical interventions, but of dismantling the power structures that sustain such health outcomes.

An intersectional approach also raises important questions about knowledge of health and the relationships of power that govern it, providing insights into what and whose knowledge is visible and who are excluded from processes of health knowledge creation. This is closely linked to the constructing of health discourse - policy, programmes, including health research.

One of the key concerns with application of the intersectional framework is about the possible delineation of differences leading to fragmentation in action and mobilization on issues, and its ability to identify complexities that emerge from the intersections but the absence of or limited scope to address them. However, analysis of multiple and intersecting forms of oppression should at the least be made visible for deliberation on how they can be addressed.

\section{Acknowledgment}

The authors work with Sama Resource Group for Women and Health based in India www. samawomenshealth.in and a part of Indian Chapter of People's Health Movement. The authors would like to acknowledge Ranjan De for reviewing and editing the article. 


\section{Collaborators}

Venkatachalam D (0000-0002-2536-5896)*, Mishra G (0000-0001-8114-306X)*, Fatima
A (0000-0002-9881-8358)*, Nadimpally S (0000-0003-2494-616X)*. Authors collaborated equally.

\section{References}

1. Nadimpally S, Fatima A. The Muzaffarpur Child Deaths Were a Predestined Tragedy [internet]. The Wire. 2019. [accessed on 2019 July 13]. Available on: https:// thewire.in/health/muzaffarpur-aes-child-deaths.

2. Hankivsky O. Intersectionality 101. Montreal: Institute for Intersectionality Research \&Policy, Simon Fraser University; 2014.

3. Perlman M. The origin of the term intersectionality [internet]. Columbia Journalism Review. 2018 [accessed on 2019 July 13]. Available on: https://www. cjr.org/language_corner/intersectionality.php.

4. Gines K. Race Women, Race Men and Early Expressions of Proto-Intersectionality, 1830s-1930s. in: Goswami N, O’ Donovam MM, Yount L, editors. Why Race and Gender Still Matter: An Intersectional Approach. New York: Routledge; 2014.

5. John M. Intersectionality - Rejection or Critical Dialogue. Econ. Polit. Weekly. 2015; 50(33). [accessed on 2020 Jan 20]. Available on: https://www.epw.in/journal/2015/33/discussion/intersectionality.html.
6. Banerjee S, GhoshN. Introduction. Debating Intersectionalities: Challenges for a Methodological Framework. South Asia multidiscip. acad. j. 2018; (19):118.

7. McGibbon E, McPherson C. Applying Intersectionality \& Complexity Theory to Address the Social Determinants of Women's Health. Toronto: UTSC Printing Services; 2015.

8. World Health Organization. Health Equity [internet]. Washington, DC: WHO. [accessed on 2019 July 13]. Available on: https://www.who.int/topics/health equity/en/.

9. World Health Organization. Declaration of Alma Ata: International Conference on Primary Health Care [internet]. Geneva: World Health Organization; 1978.

10. Hardoon D. An Economy for the $99 \%$ : It's time to build a human economy that benefits everyone, not just the privileged few. Oxfam; 2017 Jan 16.

11. Priya R, Gaitonde R, Mohit P, et al. Alma Ata and PHC 2.0.Med. Friend Circle.2019; (380):1-84. 
12. Abhiyan JS. People's Health Manifesto. Genova: PHM; 2018.

13. Sama-Resource Group for Women and Health. From the Margins to the Centre. National Human Rights Commission. 2019:23 [internet]. Sama-Resource Group for Women and Health. 2019 Nov 21. [accessed on 2019 Nov 22]. Available on:http://www.samawomenshealth.in/from-the-margins-to-the-centre/.

14. Sengupta A, Bodini C, Franco S. Struggles for Health: An Emancipatory Approach in the Era of Neoliberal Globalization. Development. 2018.

15. Global Health Watch. The current discourse on universal health coverage (UHC). London: Zed Books; 2014.

16. World Health Organization. Tracking universal health coverage: first global monitoring report. Paris: WHO; 2016.

17. The World Bank. Data retrieved [internet]. [accessed on 2019 Mar 3]. Available on: https://data.worldbank.org/country/india.

18. National AIDS ControlOrganisation. Data Retrieved [internet]. [accessed on 2019 Mar 3]. Available on: http://naco.gov.in/hiv-facts-figures.
19. United Nations Development Programme. Human Development Report India Factsheet. Gender and Social Exclusion Indicators [internet]. [accessed on 2019 Mar 3]. Available on: http://www.in.undp.org/ content/dam/india/docs/india_factsheet_gender_n_ social_exclusion_indicators.pdf.

20. Gupte M. International Women and Health Meeting, 2011, Belgium; Opening Plenary.

21. Global Health Watch Report (4). Reframing health in Bolivia around the concept of 'living well'. London: Zed Books; 2014.

22. India. NavtejSinghJohar vs Union of Indial SCC 791. Ministry of Law and Justice. 6 Sept 2018.

23. India. National Legal Services Authority v. Union of India \& OthersAIR 2014 SC 1863. Ministry of Law and Justice. 15 Apr 2014.

24. Greece Solidarity Campaign. Solidarity Clinics. [internet]. [accessed on 2020 Jan 14]. Available on: http:// greecesolidarity.org/?page_id=1114.

\footnotetext{
Received on 10/04/2019

Approved on 12/12/2019

Conflict of interests: non-existent

Financial support: non-existent
} 